A INCIDÊNCIA DO ART. 186 DO CÓDIGO CIVIL BRASILEIRO NO ABANDONO AFETIVO DOS PAIS. É POSSÍVEL?

ANTONIO DANTAS DE OLIVEIRA JÚNIOR 


\section{A INCIDÊNCIA DO ART. 186 DO CÓdIGO CIVIL BRASILEIRO NO ABANDONO AFETIVO DOS PAIS. É POSSÍVEL?}

Antonio Dantas de Oliveira Júnior ${ }^{1}$

\section{RESUMO:}

O presente trabalho visa uma reflexão e suas consequências acerca da falta de assistência, no mundo contemporâneo, dos pais em relação aos filhos, o que vem acarretando graves transtornos no âmbito familiar, social e psicológico do infante. A matéria não está pacificada nos tribunais brasileiros sobre a possibilidade da reparação civil de danos, mas é sensato que a indenização deva ser utilizada como ultima ratio, nos casos em que a aproximação e o afeto entre pais e filhos são, praticamente, inviáveis, quando houver culpa paternal.

Palavras-chave: Reparação Civil. Abandono Parental. Afeto. Invisibilidade Emocional. Responsabilidade Subjetiva.

\section{RESUMEN:}

Este trabajo es la reflexión sobre la falta de asistencia, en el mundo contemporáneo, los padres de los niños, que viene con trastornos graves en familia, social y psicológico do infante. La indemnización, en esta situación, debe utilizarse como ultima ratio, en casos donde es prácticamente imposible, el enfoque y el afecto entre padre e hijo por culpa de sus padres.

Palabra-clave: Reparación Civil. Abandono Paterno. Afecto. Invisibilidad Emocional. Responsabilidad Subjetiva.

\footnotetext{
1 Juiz de Direito Titular na Comarca de Aurora do Tocantins, Graduado pela Universidade Tiradentes - SE, em 1998; Pós-Graduado em Direito Processual Civil pela Universidade Tiradentes - SE, em 2000, e em Direito Tributário pela Universidade Cândido Mendes RJ, em 2003. Idealizador, em 2010, do Projeto Social "Aprendendo a Pensar" na Comarca de Aurora do Tocantins.
} 


\section{INTRODUÇÃO}

Sistematizando o conteúdo deste artigo é importante tecer comentários sobre a família como nascedouro nas primitivas formas de agrupamentos humanos, no início preocupada com a perpetuação da espécie e o caráter produtivo no campo, mas que, com a revolução industrial fez surgir o aumento da necessidade de mão de obra e do trabalho da mulher, tendo acarretado uma migração dos campos para as cidades, em moradias menores, aproximando os seus integrantes e configurando um novo conceito de família baseado em laços afetivos.

Atualmente, com a evolução, a família é baseada na concepção da multiplicidade, não pautada, apenas, no casamento entre homem e mulher, isto é, o perfil biológico, afetivo... está, no seu formato, inserido no conceito de família, desde que prime pelo crescimento da personalidade de seus integrantes, oportunizando a criação de outros modelos de entidades familiares, como a monoparental (entre um dos pais e a prole), a união estável e, recentemente, com o reconhecimento pelo Supremo Tribunal Federal, a homoafetiva.

No mundo moderno, em especial no Brasil, percebe-se uma forte influência do Direito Constitucional sobre o Direito Privado. Assim, tem-se como princípio reitor desta tendência a dignidade da pessoa humana, fundamento da República Federativa do Brasil (Art. $1^{\circ}$, inciso III, da $\mathrm{CF} / 88^{2}$ ), o que foi 
confirmado no art. $3^{\circ}$, inciso IV, da Carta Magna, como objetivo da República Federativa do Brasil " promover o bem de todos, sem preconceitos de origem, raça, sexo, cor, idade e quaisquer outras formas de discriminação"(Grifos nossos). A promoção do bem de todos, nada mais é, senão a garantia da dignidade da pessoa humana e o respeito ao diferente em uma sociedade multifacetária.

Visualiza-se, portanto, o estudo do Direito Privado à luz da força normativa constitucional, como por exemplo: o Direito Civil - Constitucional. Percebe-se que o Direito Civil Pátrio está passando por uma verdadeira mutação de pensamento e de atitude diante do que a doutrina intitula de descodificação, através de vários microssistemas (Código de Defesa do Consumidor, Estatuto da Criança e do Adolescente, Estatuto do Idoso, etc.) e, por conseguinte, a Carta Magna, em uma relação vertical, no ápice da pirâmide, auxiliando a resolução de inúmeras questões ligadas, em especial, ao direito de família(abandono afetivo dos pais).

Dessa forma, o Direito Civil passa por um processo de despatrimonialização, mormente, com a reforma ocorrida em 2002, a qual se adequou ao Texto Constitucional, ou seja: as relações interpessoais devem ser observadas e priorizadas, verbis gratia, os direitos da personalidade, a indenização do dano moral, a boa-fé objetiva (...).

Adentrando no dano extrapatrimonial, no âmbito das relações familiares, considero em tese ser viável e perfeitamente possível à reparação civil, desde que o magistrado valha-se de 
extrema cautela e analise o caso concreto com razoabilidade e atendimento aos requisitos legais.

\section{LEGISLAÇÃO}

Trago à baila o artigo 186, do Código Civil Brasileiro ${ }^{3}$, verbis:“Aquele que, por ação ou omissão voluntária, negligência ou imprudência, violar direito e causar dano a outrem, ainda que exclusivamente moral, comete ato ilícito". (Grifos Nossos).

O Superior Tribunal de Justiça, acerca do assunto, exarou a Súmula $n^{\circ} 37^{4}$, litteris: "São cumuláveis as indenizações por dano material e dano moral oriundos do mesmo fato". (Grifos Nossos).

Em ações desta natureza, as correntes maniqueístas não podem prevalecer, sob pena de gerar uma total monetarização das relações afetivas ou o descumprimento das Normas Constitucionais, do Estatuto da Criança e do Adolescente, Súmulas e da Legislação Alienígena sobre Direitos Humanos. O direito de família, por essência, deve resgatar e priorizar, como primeira medida, o respeito mútuo entre as pessoas.

A Convenção sobre os Direitos da Criança ${ }^{5}$, adotada em Assembleia Geral das Nações Unidas, em 20 de novembro de 1989 , menciona, em seu art. 7.1, ser direito da criança "a

3 BRASILEIRO. Código Civil. $8^{a}$ ed. São Paulo. Revista dos Tribunais, 2011.

4 VADE MECUM. $12^{\mathrm{a}}$ ed. São Paulo. Rideel. 2011.

5 BRASIL SANTOS. Indenização por abandono afetivo. Adv: seleções juridicos. São Paulo, p. 25-26, 2005. 
conhecer seus pais e a ser cuidada por eles", (Grifos Nossos).

A Carta de Outubro ${ }^{6}$, no caput do art. 227 , reza que é dever, como primeiro passo da família preservar, dentre outros, o Direito da Criança e do Adolescente à "convivência familiar", e "colocá-los a salvo de toda a forma de negligência (...)". (Grifos Nossos).

O Estatuto da Criança e do Adolescente (Lei $\mathrm{n}^{\circ}$ $8069 / 90)^{7}$, ratifica o direito da criança e do adolescente "a ser criado e educado no seio de sua família" (Art. 19), acarretando aos genitores "o dever de sustento, guarda e educação dos filhos menores" (Art. 22) (Grifos Nossos).

O Código Civil Brasileiro ${ }^{8}$, em seu artigo 1.566 e inciso IV, suscita entre os deveres conjugais o de "sustento, guarda e educação dos filhos", e, conforme determinado nos artigos 1.584 e 1.586, a observância do princípio que atenda o melhor interesse do infante, no caso de separação ou divórcio dos pais. (Grifos Nossos).

A idéia central da Legislação Civil Brasileira, em harmonia com a Constituição Federal e as Convenções Internacionais é a preservação da criação, educação e convívio por parte dos pais, em relação aos filhos para, no futuro, não incidir consequências psíquicas na formação do menor.

\begin{tabular}{ll}
\hline 6 & Idem 01. \\
7 & Idem 03. \\
8 & Idem 02.
\end{tabular}




\section{ASPECTOS PSICOLÓGICOS E O DIREITO DA PERSONALIDADE}

Segundo textualiza a doutrina especializada, peritos em psicologia têm confirmado que a criança abandonada por seu pai sofre trauma e ansiedade, fatores que repercutirão em futuras relações, com sensível perda de confiança e auto-estima, o que vai de encontro ao conceito presente de família que é baseado na proteção dos direitos da personalidade.

Diante do já expositado, surge a seguinte pergunta: a paternidade e a maternidade são tão somente biológicas? No meu sentir, não. Ser pai pressupõe um dado socioafetivo estabelecido na convivência e não é uma mera decorrência do vínculo genético, como se fosse apenas um reprodutor para garantir a sobrevivência da espécie.

Seguindo a linha dos direitos da personalidade, os atributos físicos, psíquicos e morais de um indivíduo devem ser sopesados, eis que a pessoa humana é o ponto central da Ordem Jurídica Brasileira, seja em corpo, seja em alma e seja em intelecto.

Não é outro o dizer do Professor Marcos Ehrhardt Jr. ${ }^{9}$ :

Podemos definir como direito da personalidade aqueles direitos subjetivos reconhecidos à pessoa para a garantia de sua dignidade, vale dizer, para a tutela dos seus aspectos físicos, psíquicos e intelectuais, dentre outros não mensuráveis economicamente, porque dizem respeito

9 JR. Marcos Ehrhardt. Direito Civil: volume I. Salvador.: Jus Podvim, 2009. p. 187.

Revista Esmat, Palmas, Ano 3, n 3, pag. 33 a 56 - jan/dez 2011 


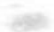

à própria condição da pessoa, ou seja, ao que lhe é significativamente mais intimo... (Grifos Nossos).

Diante das segregações cometidas contra a humanidade pelo nazismo na época da Segunda Guerra Mundial, adveio a promulgação da Declaração Universal dos Direitos do Homem e, como extensão, a proteção dos direitos da personalidade que, tempos depois, foi prevista em várias Constituições, mundo afora, para assegurar o mínimo necessário aos seres humanos, garantindo a dignidade e a proteção de direito fundamentais.

Então, o que é mínimo? O que é digno?

Respondo: Como regra, o que é digno para uma pessoa, talvez não seja para outra, eis que a "história" de vida de cada indivíduo irá conceber a definição de mínimo, porém existem situações que a noção de dignidade, de mínimo deve ser analisada, no caso em exame, pelo Poder Judiciário, quando de um julgamento e pelo Poder Legislativo, no ato de elaboração e aprovação de uma lei, evitando abusos daqueles que se sentem afrontados e crêem na liberdade absoluta para dizerem o que é ou não minimalidade.

Uma das características marcantes dos direitos da personalidade é a irrenunciabilidade, daí o possível ofendido não pode dispô-lo, apesar de ser possível a violação. No caso em apreciação, o filho menor abandonado, mesmo que consinta com a omissão paterna, não apaga o seu direito de ser cuidado por este. 
$\mathrm{O}$ artigo 11, do Código Civil Brasileiro ${ }^{10}$, reza: “Com exceção dos casos previstos em lei, os direitos da personalidade são intransmissíveis e irrenunciáveis, não podendo seu exercício sofrer limitação voluntária."(Grifos Nossos).

Por isso, a afetividade, o amor, o carinho (...), são indispensáveis ao convívio entre pais e filhos, caso contrário haverá lesão à dignidade moral destes. Destarte, a ofensa a um direito da personalidade acarreta a possibilidade da reparação civil, no caso, subjetiva e, imprescindivelmente, devem restar comprovados os requisitos previstos no art. 186, do Código Civil Brasileiro (culpa do agente, existência de dano e nexo de causalidade).

$\mathrm{Na}$ legislação brasileira hodierna não há nenhuma proibição de utilizar o instituto da responsabilidade civil nas relações familiares. O princípio da legalidade na seara privada é devidamente cumprido quando o indivíduo faz tudo aquilo que não está proibido por lei. Na presente questão, como já dito, o artigo 186, do Código Civil Brasileiro, prevê a possibilidade da reparação quando do surgimento de um dano moral.

A propósito da matéria cito as considerações do Eminente Professor Rolf Madaleno ${ }^{11}$ :

A responsabilidade civil no Direito de Família é subjetiva, exige um juízo de censura do agente capaz de entender o caráter de sua conduta ilícita. É preciso demonstrar sua

$10 \quad$ Idem 02.

11 MADALENO, Rolf. O Dano Moral na Investigação de Paternidade. Revista da Ajuris, $\mathrm{n}^{\circ} 71$, p. 275. 
culpa, tanto que Sérgio Cavalieri Filho observa que: "A vítima de um dano só poderá pleitear ressarcimento de alguém se conseguir provar que esse alguém agiu com culpa; Caso contrário, terá que se conformar com sua má sorte e sozinha suportar o prejuizo"(Grifos Nossos).

$\mathrm{Na}$ situação em comento, não se está falando em indenização por falta de amor dos pais em relação aos infantes, pois amor e afeto devem ser doados espontaneamente. A reparação civil deve ocorrer por violação de deveres paternais que causem danos, por exemplo: o abandono premeditado.

\section{O PODER FAMILIAR E O DANO MORAL}

No direito posto, enquanto menores, os filhos estão sujeitos ao poder familiar dos pais, ou seja, a obrigação, destes últimos, de velar e zelar por sua prole. Na prática, infelizmente, o que acontece, com muita freqüência, é o pai, após o divórcio ou com o fim do amor pela esposa/companheira, abandonar, covardemente, os próprios filhos no aspecto material e, sobretudo, no afeto, acarretando uma série de tormentas ao invisível emocional que, muitas vezes entra no mundo das drogas, abandona os estudos, comete atos infracionais (...), como forma de chamar a atenção e ser visto e ouvido no seio da própria família e da sociedade.

$\mathrm{O}$ artigo 1.634, do Código Civil Brasileiro enumera 07 (sete) deveres dos pais em relação à pessoa dos filhos menores, dentre eles: 
a) Condução da criação e educação;

b) Tê-los em sua companhia e guarda;

c) Conceder-lhes ou negar-lhes consentimento para casarem.

(...).

No rol supracitado, não consta que os pais têm o dever de dar amor, carinho e afeto aos seus filhos menores (condutas ligadas aos sentimentos e que não podem ser impostas). O que, no meu entender, fora acertado, porque o dever dos genitores é a criação, a educação, a administração e o usufruto dos bens daqueles.

O descumprimento do poder familiar pode acarretar aos pais a suspensão ou extinção desse poder, porém esta sanção não é eivada de caráter punitivo, mas para proteger o incapaz. Para " ilustrar, um pai ou uma mãe que deixar o filho em abandono terão extintos o poder familiar. E qual é a conseqüência? A infração ao dever de criação acarreta o crime de abandono material, com previsão no artigo 244 , do CP e enquadra-se na citada figura da perda do poder familiar.

E o dano moral é permitido?

Segundo a doutrina, acerca da ilicitude, e aqui também partilho, em uma relação familiar deve haver a incidência dos artigos 186 e 187 do Código Civil Brasileiro, o que fora aceito pelo Superior Tribunal de Justiça ${ }^{12}$ nos seguintes termos:

12 STJ, Ac $3^{\mathrm{a} T}$., REsp.37.051//SP, rel Min. Nilson Naves, j.17.4.01, in Revista Forense, p. $363: 240$. 


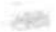

o sistema jurídico brasileiro admite, na separação e no divórcio, a indenização por dano moral. Juridicamente, portanto, tal pedido é possível: responde pela indenização o cônjuge responsável exclusivo pela separação; caso em que, diante do comportamento injurioso do cônjuge varão, a Turma conheceu do Especial e deu provimento ao recurso, por ofensa ao art. 159 do Código Civil de 1916(art. 186 do $\mathrm{CC} / 02$ ), para admitir a obrigação de se ressarcirem danos morais (STJ, Ac 3 ${ }^{\mathrm{a}}$ T., REsp.37.051//SP, rel Min. Nilson Naves, j.17.4.01, in Revista Forense 363:240).

A problemática que surge é em relação à abrangência da ilicitude, pois para uma parte da doutrina a indenização nas relações familiares é possível em casos gerais (arts. 186 e 187 do $\mathrm{CCB}$ ) e, para outra, a reparação civil seria concedida em situações específicas oriundas de violações inerentes aos deveres matrimoniais, por exemplo, o ataque a fidelidade recíproca geraria a possibilidade de um dano moral.

É prudente que nas relações familiares o ter não se sobreponha ao ser, daí a melhor corrente é aquela que possibilita a reparação civil no direito de família quando houver, efetivamente, a prática de um ato ilícito, no modelo dos artigos 186 e 187 do CCB. Assim, o adultério pelo adultério, por si só, não pode ser causa de indenização. $\mathrm{O}$ abandono pelo abandono de um pai ou de uma mãe, por si só, em relação a um filho, de igual modo, não é causa de indenização, caso contrário haveria a utilização do dano moral in re ipsa, inaceitável, ao menos, para mim, no direito de família.

Por sua vez, seguindo uma linha naturalista, o dever de 
afeto é condição sine qua non entre pais e filhos, ao menos, como todo animal irracional, instintivamente. Não há dúvida, repito, que o amor não pode ser imposto entre os genitores, tampouco, entre pais e filhos, porque afeto é conquista e reclama reciprocidade.

Independentemente da presença ou não de um pai na vida do filho, o fundamental é que o menor seja educado em um ambiente equilibrado, porém, este fato, não exime, caso haja, a responsabilidade civil paternal ou maternal por omissão.

\section{A JUDICIALIZAÇÃO DO AFETO E A PERDA DE UMA CHANCE}

Pensemo-nos: o Estado-Juiz tem o poder de obrigar os pais a sentirem carinho pelos filhos? Não. Entrementes, o Poder Judiciário deve, quando provocado, responsabilizar civilmente o genitor por abandono afetivo, em razão do descumprimento do dever de criar, educar e conviver com o filho, em harmonia, como alhures dito, com o art. 186, do Código Civil Brasileiro.

A Professora Maria Berenice Dias, em seu Manual de Direito das Famílias ${ }^{13}$, aduz que:

(...) Daí a atual orientação jurisprudencial que reconhece a responsabilidade civil do genitor por abandono afetivo, em face do descumprimento do dever inerente à autoridade parental de conviver com o filho, gerando obrigação

13 DIAS. Maria Berenice. Manual de direito das familias. 6. ed. São Paulo. Revista dos Tribunais, 2010 
indenizatória por dano afetivo (...) (Grifos Nossos).

No início deste artigo falou-se na constitucionalização do direito civil e, com isso, quando a solidariedade social e a dignidade de uma pessoa são atingidas a indenização éaceita como uma premissa lógica-norma da lesão às garantias fundamentais. Não se está falando de dano moral, nem patrimonial, mas da perda de uma chance no direito de família.

$\mathrm{O}$ instituto em comento é aquele que possibilita a alguém obter um benefício caso não seja retirada à oportunidade, mesmo que com chances ínfimas, mas reais. No caso, não se indeniza a perda de um resultado querido, porém a perda da possibilidade de conseguir alguma vantagem.

O Superior Tribunal de Justiça ${ }^{14}, 4^{\mathrm{a}}$ T., REsp. 788.459/ BA, rel Min. Fernando Gonçalves, j.8.11.05, DJU 13.3.06, p. 334, estabeleceu:

Impropriedade de pergunta formulada em programa de televisão. Perda da oportunidade. O questionamento, em programa de pergunta e respostas, pela televisão, sem viabilidade lógica, uma vez que a Constituição Federal não indica percentual relativo às terras reservadas aos índios, acarreta, como decidido, pelas instâncias ordinárias, a impossibilidade da prestação por culpa do devedor, impondo o dever de ressarcir o participante pelo que razoavelmente haja deixado de lucrar pela perda da oportunidade.

$14 \quad 4^{a}$ T., REsp. 788.459/BA, rel Min. Fernando Gonçalves, j.8.11.05, DJU 13.3.06, p. 334. 
A perda de uma chance é aplicável ao direito de família? Sim. Explico: O infante abandonado de maneira intencional, negligente, omissa, etc., pelos pais, perdeu a chance de desfrutar da plenitude em família e, por isso, a indenização é devida, inclusive, por ofensa ao princípio do solidarismo familiar. Agora, não configura a perda de uma chance o fato de um pai ou de uma mãe não dar carinho, amor e atenção ao filho, eis que sentimento é do espírito e não tem como ser quantificado.

Como se depreende, não pode haver a judicialização impositiva do amor, eis que o Estado não possui legitimidade para tal, porquanto o norte moral do indivíduo é o livre arbítrio (amar, odiar, zelar, maltratar...). É surreal imaginar que o EstadoJuiz possa, com a fixação de uma indenização, obrigar alguém a amar outrem, eis que a falta de amor ou de afeto não pode e não deve ser considerada ato ilícito, fugindo à seara do Direito Positivo.

Tomando como paralelo o Direito Penal, percebe-se que os preceitos primários delitógenos não são proibitivos, mas descritivos, preservando a liberdade de escolha de cada ser humano. $\mathrm{O}$ mesmo raciocínio deve ser utilizado em relação à ausência de afeto, contudo com uma única diferença: a prisão do infrator é a cadeia, e a do pai ou mãe desafetuosos é a própria consciência.

O preâmbulo da Mens Legis assegura a figura do Estado Laico e a crença em "Deus", respeitando as diferenças, dentre elas, o indivíduo que é ateu.

Indaguemo-nos: É possível aplicar uma sanção a quem 
não acredita em Deus? A resposta somente pode ser negativa; assim como aplicar uma indenização ao pai que não sente amor e afeto pelo filho, haja vista que a sanção pecuniária não vai forçar o ateu a acreditar em Deus e nem o pai a amar o filho.

\section{PRINCÍPIO DO VENIRE CONTRA FACTUM PROPRIUM}

Antes de entrar, necessariamente, no estudo deste princípio é de bom alvitre tecer alguns comentários sobre o princípio da boa-fé objetiva que, outrossim, deve ser aplicado ao direito de família. Veja-se: a boa-fé objetiva impõe um padrão de conduta de modo que um ser humano deve agir com retidão, honestidade e lealdade nos padrões do homem médio.

Os pais que entregam ao relento seus próprios filhos agem com retidão, e como um homem mediano agiria? Não, pois há uma quebra de duas funções inerentes à boa-fé objetiva, são elas:

a) Função Criadora de Deveres Anexos: É o dever que os pais têm de agir com cuidado e com transparência em relação aos filhos.

b) Função Integrativa: Os pais abusam do direito que possuem no que tange à prole, vilipendiando a confiança e, como conseqüência, privando os filhos da sua companhia.

De plano, a boa-fé objetiva é aplicável nas relações contratuais, porém como o Código Civil, reformado em 2002, está preocupado com o ser e o fundamento jurídico da função 
social é a dignidade da pessoa humana, não vejo óbice à sua aplicação nas relações parentais.

Assim, como conseqüência deve ser utilizado o princípio da proibição do comportamento contraditório, em razão da quebra de confiança, nas relações de família. Explico: o pai ou a mãe geram uma expectativa nos filhos que vão cuidar, educar e conviver com eles, porém, sem respeitar o critério do homem médio, abandonam o infante, acarretando uma mudança de comportamento, diante da contradição.

Dessar't, a indenização, igualmente, é viável em consonância com o art. 186 do CCB.

\section{CONTROVÉRSIAJURISPRUDENCIALEADOUTRINA}

O Superior Tribunal de Justiça no Recurso Especial $\mathrm{n}^{0} 514.350-\mathrm{SP}^{15}$, não aceitou à reparação civil de danos por abandono paternal, suscitando que o judiciário não pode obrigar alguém a amar ou a manter um relacionamento afetivo.

Mister se faz transcrever ementa do Acórdão acima mencionado, in verbis:

RESPONSABILIDADE CIVIL. ABANDONO MORAL. REPARAÇÃO. DANOS MORAIS. IMPOSSIBILIDADE. 1. A indenização por dano moral pressupõe a prática de ato ilícito, não rendendo ensejo à aplicabilidade da norma do artigo 159, do Código Civil de 1916, o abandono afetivo, incapaz de reparação pecuniária.

$15 \quad 4^{\mathrm{a}}$ Turma, Resp. $\mathrm{n}^{\circ} 757.411 / \mathrm{MG}$, Rel. Min. Fernando Gonçalves, unanimidade, DJU de 29.11.2005. 
2. Recurso Especial conhecido e provido" (4 $4^{\mathrm{a}}$ Turma, Resp. $\mathrm{n}^{\circ}$ 757.411/MG, Rel. Min. Fernando Gonçalves, unanimidade, DJU de 29.11.2005).

Os Tribunais de Justiça Brasileiros, em especial, o do Rio Grande do Sul estão abalizando que a omissão afetiva no âmbito do direito familiar é, sabidamente, de interpretação restritiva e não se configura pelo simples fato de os pais não terem reconhecido, de pronto, o filho, como também não há dano o mero distanciamento afetivo entre pais e filho, por circunstâncias de fato da vida. É preciso a análise do caso concreto e o preenchimento do determinado no artigo 186 do CCB.

A Professora Maria Celina Bodim de Morais ${ }^{16}$, assinala que:

O que é preciso distinguir é se o pai sabia ou não da existência do filho e se se negou ou não a reconhecê-lo. A responsabilidade, em todos esses casos, é subjetiva, e será preciso demonstrar a negligência do pai. Se este não tinha conhecimento da existência do filho, evidentemente não poderá ser responsabilizado pela falta de convivência; se fazia alguma vaga idéia, mas não se negou a reconhecê-lo, tampouco deverá ser responsabilizado pelo reconhecimento não espontâneo. Outra será a situação quando se prove (e a prova é imprescindível) que tinha conhecimento e se negou ao reconhecimento, quando então caberá a reparação por abandono afetivo. (Grifos Nossos).

16 MORAES. Maria Celina Bondin de. Familia: do autoritarismo ao afeto - como e a quem indenizar a omissão do afeto? Revista Brasileira de Direito de Família, n 32, p. 20/39. 
O receio de parte da doutrina e jurisprudência acerca das indenizações nas relações parentais de abandono é que o genitor condenado, como represália, jamais tornará a se aproximar do rebento. Será?

O que precisa em situações deste jaez é o magistrado, apoiado por profissionais habilitados, compreender o verdadeiro sentido da ação reparatória e, a priori, buscar a composição entre pai e filho, objetivando auxiliar o resgate ou iniciar a possibilidade de entendimento entre eles.

De mais a mais, em determinados casos, malsinadamente, o restabelecimento do amor e do carinho é, praticamente, impossível, pois já fora desfeito pelo longo tempo transcorrido diante de total ausência de contato e de afeto paterno. De outro lado, o que impera é a própria personalidade e conceitos de vida da figura paterna, daí, a pena indenizatória precisa ser aplicada, em alguns casos, com o escopo de reparar o reversível prejuízo causado ao filho que sofreu pela ausência do pai.

Uma pessoa que nunca foi amada, como pode amar? Alguém que não conhece o poder do abraço, como pode abraçar? Outrem, que não conhece a beleza do sentimento do beijo, como pode beijar? Dessa maneira, o judiciário deve respeitar a liberdade das escolhas, fruto de uma sociedade plural, todavia não poderá compactuar com o abandono irresponsável de pais que se vêem, meramente, como procriadores.

Enfim, a reparação civil resta caracterizada com a conduta ilícita, com culpa, do pai em relação ao filho, o nexo de causalidade e o dano. Esta indenização deve ser a ultima ratio 
do julgador.

De outra banda, a liberdade parental está subdividida em dois aspectos:

a) Objetivo: são os direitos e deveres dos pais que inobservados, no aspecto material, geram ações de alimentos; e no aspecto extrapatrimonial, a perda do poder familiar (inciso II, art. 1.638, do Código Civil Brasileiro). Entendo que existe o direito indenizatório do filho, desde que haja ofensa aos preceitos constitucionais e infraconstitucionais (proteção, educação, convivência, o princípio da dignidade da pessoa humana, o princípio do ser em desenvolvimento, etc.), atendendo o disposto no artigo 186 da Legislação Substantiva Civil.

b) Subjetivo: a autonomia afetiva dos pais de conceder ou não afeto aos filhos. In casu, não gera nenhuma conseqüência sob pena de ferir o direito à liberdade paterna de escolher os próprios sentimentos.

\section{CONCLUSÃO}

O afeto é impagável, e não pode substituir a grandeza de um abraço e de um beijo entre pai efilho, entretanto, odescumprimento dos deveres paternais, em uma responsabilização subjetiva (art. 186, do CCB), deve ensejar uma ação indenizatória, como forma punitiva e dissuasória.

O sonho de todo filho e do próprio magistrado, em ações de investigação de paternidade é ver, quando de um julgamento procedente, o pai se vendo emocionalmente como pai. Na prática 
forense, e pela lei natural da vida não é assim que procede, posto que a construção afetiva é baseada no dia-a-dia, na convivência, o que corrobora a tese de que o liame biológico não é suficiente para uma pessoa ser pai na acepção da palavra.

Realmente a matéria é polêmica e instiga o estudo da responsabilidade civil, em especial, no que tange aos danos extrapatrimoniais. Para que uma pessoa tenha vida plena é preciso que haja dignidade, segundo o caput, do Art. $5^{\circ}$, da Constituição Federal, todavia um menor abandonado moralmente pelo pai não possui a oportunidade de ser cuidado, educado e ter a companhia dele, ocasionando a quebra dos princípios da dignidade da pessoa humana, da boa-fé objetiva e do Venire contra factum proprium nas relações familiares.

É justo que um pai omisso tenha como punição, somente, a perda do poder familiar? No meu modo de pensar, não, porquanto seria um prêmio para genitores descompromissados afetivamente com sua prole, eis que estariam "isentos" de qualquer "trabalho educativo e emocional" no crescimento moral da criança. E não venham dizer que a fixação de alimentos seria uma "punição" aos pais omissos, porque não o é, eis que os alimentos estão relacionados à dignidade humana do filho, aos direitos da personalidade e a solidariedade familiar.

É preciso mostrar à sociedade que condutas dessa natureza acarretam não só a ruptura do poder familiar, mas principalmente uma reparação pecuniária para que, ao menos, seja motivo de reflexão por parte de pais irredutíveis em suas condutas, servindo assim de desestímulos a todos aqueles que 
abdiquem do dever de cuidar dos seus filhos.

Uma coisa é aquele genitor (a) que, por circunstâncias adversas da vida, afasta-se do filho, porém, é pautado de sentimentos de amor e responsabilidade; e outra coisa é a figura paterna e/ou materna que, por intencionalidade, não conseguirão, durante uma vida, demonstrar nenhum sentimento positivo acerca da prole.

Como se vê, só o caso concreto poderá definir se será ou não cabível uma indenização por abandono afetivo parental, e a pecúnia aqui citada não é pelo fato da ausência de amor e sim por descumprimento dos deveres de pai e mãe.

Nãosepode negar, em casos ondeháa efetiva comprovação de negativa de amparo afetivo, moral e psicológico a um filho há violação, clarividente, dos direitos da personalidade (honra, dignidade, reputação social...) e, portanto, passível de reparação civil (Art. $5^{\circ}$, inciso X, da Constituição Brasileira).

Na dificultosa problemática, a melhor saída é a triagem dessas ações, quando interpostas judicialmente, antes do despacho positivo, por profissionais da área de saúde vinculados ao Poder Judiciário, visando dirimir, em sua base, a premissa principal do problema, qual seja: a reaproximação entre pais e filhos, sendo a lide o último procedimento.

Por fim, sintetizando o que fora, aqui, instigado, cito os dizeres, com uma pertinência ímpar, do Professor Luiz Edson Fachin ${ }^{17}$ : "mais que fotos na parede, quadros de sentido, a 
família há de ser, possibilidades de convivência”.

\section{REFERÊNCIAS BIBLIOGRÁFICAS}

DIAS, Maria Berenice Dias. Manual de direito das famílias. 6. ed. São Paulo: Revista dos Tribunais, 2010.

FACHIN, Luiz Edson. Elementos críticos do direito de família: curso de direito civil. Rio de Janeiro: Renovar, 1999.

FARIAS, Cristiano Chaves de, ROSENVALD, Nelson. Direito das famílias. Rio de Janeiro: Lumen Júris, 2008.

Cunha JR. Dirley da. NOVELINO, Marcelo. Constituição Federal para concursos: volume 1. Salvador: Jus Podivm, 2010.

Ehrhardt JR, Marcos. Direito Civil: LICC e parte geral, volume I. Salvador: Jus Podivm, 2009.

Nery JR, Nelson. NERY, Rosa Maria de Andrade. Código Civil comentado. 8.ed. São Paulo: Revista dos Tribunais, 2011.

LENZA, Pedro. Direito constitucional esquematizado. 14. ed. São Paulo: Saraiva, 2010.

MORAES. Maria Celina Bondin de. Família: do autoritarismo ao afeto - como e a quem indenizar a omissão do afeto? Revista 
Brasileira de Direito de Família, n. 32, p. 20/39

MADALENO, Rolf. Repensando o Direito de Família. Porto Alegre: Livraria do Advogado, Ed. 2007.

SANTOS, Brasil. Indenização por abandono afetivo. Adv: seleções jurídicos: São Paulo, 2005.

STJ. Recurso Especial n ${ }^{\circ}$ 514.350-SP. Rel. Min. Aldir Passarinho Júnior.

TJ-RS. Apelação Cível n ${ }^{\circ} 70021427695,8^{a}$ Câmara Cível, Rel. Des. Claudir Fidélis Faccenda.

TJ-RS. Apelação Cível n $70029285277,7^{\text {a }}$ Câmara Cível, Rel. José Conrado de Souza Júnior.

TJ-RS. Apelação Cível no $70022661649,7^{\text {a }}$ Câmara Cível, Rel. André Luiz Planella Villarinho.

TJ-RS. Apelação Cível n $70026680868,7^{\circ}$ Câmara Cível, Rel. Sérgio Fernandes de Vasconcelos.

TJ-RS. Apelação Cível n ${ }^{\circ} 70034280040,7^{\circ}$ Câmara Cível, Rel. José Conrado de Souza Júnior.

VADE MECUM. 12a ed. São Paulo: Rideel, 2011. 